Article

\title{
Digital-Networked Images as Personal Acts of Political Expression: New Categories for Meaning Formation
}

\author{
Mona Kasra \\ Department of Drama, University of Virginia, Charlottesville, VA 22904, USA; E-Mail: mona.kasra@virginia.edu
}

Submitted: 9 June 2017 | Accepted: 18 August 2017 | Published: 21 December 2017

\begin{abstract}
This article examines the growing use of digital-networked images, specifically online self-portraits or "selfies", as deliberate and personal acts of political expression and the ways in which meaning evolves and expands from their presence on the Internet. To understand the role of digital-networked images as a site for engaging in a personal and connective "visual" action that leads to formation of transient communities, the author analyzes the nude self-portrait of the young Egyptian woman Aliaa Magda Elmahdy, which during the Egyptian uprisings in 2011 drew attention across social media. As an object of analysis this image is a prime example of the use of digital-networked images in temporally intentional distribution, and as an instance of political enactment unique to this era. This article also explains the concept of participatory narratives as an ongoing process of meaning formation in the digital-networked image, shaped by the fluidity of the multiple and immediate textual narratives, visual derivatives, re-appropriation, and remixes contributed by other interested viewers. The online circulation of digital-networked images in fact culminates in a flow of ever-changing and overarching narratives, broadening the contextual scope around which images are traditionally viewed.
\end{abstract}

\section{Keywords}

Arab Spring; feminist art; online images; political expression; self-portrait; selfies; social media; visual communication

Issue

This article is part of the issue "Visual Communication in the Age of Social Media: Conceptual, Theoretical and Methodological Challenges", edited by Uta Russmann (FHWien der WKW University of Applied Sciences for Management \& Communication, Austria) and Jakob Svensson (Malmö University, Sweden).

(C) 2017 by the author; licensee Cogitatio (Lisbon, Portugal). This article is licensed under a Creative Commons Attribution 4.0 International License (CC BY).

\section{Introduction}

The profusion of online images disseminated by mobile communication devices onto social media, and particularly in near-immediate response to social, cultural, or political events is indicative of a contemporary phenomenon in which "digital-networked images" have become deliberate, individual acts of political identity where post-state expression of ideological commitment is enacted (Kasra, 2017). Made or captured primarily by non-professionals for social media distribution through means of participatory communication, digitalnetworked images increasingly function as a new venue for political advocacy and engagement. The accessibil- ity, affordability, and immediacy of expression brought about by new technology continuously allow networked, global citizens to participate independently in civic discourse without the structure, affiliation, or constraint associated with traditional political agency. Indeed, imagebased activism via snapshots, avatars, and selfies not only has the power to bend the rules that have historically defined and determined a political organization's purpose or direction, but to also construct new collective, political, and protest identities on social media (Gerbaudo, 2015). "Image activists" in fact sometimes participate in civic engagement independent even of others who share their ideological point of view but who may disagree with the style of expression. ${ }^{1}$

\footnotetext{
${ }^{1}$ In the past decade, social media users have increasingly used images, memes, avatars and selfies to mobilize, organize and participate in globalized politics (Kraidy, 2016; Kuntsman, 2016; Mottahedeh, 2015; Van Zoonen, Vis, \& Mihelj, 2010) or construct new collective identities (Gerbaudo, 2015).
} 
Although the impact and visibility of these images is sometimes fleeting and short-lived, as they may be forgotten and submerged in the cacophony of newly uploaded photographs and videos or follow-on news stories, by circulating across social media digital-networked images are increasingly effective in provoking action and influencing viewers' political judgment in empowering new ways. Activist-images are also just as likely to linger perpetually, as they are shared and re-shared in innumerable spaces, stored on accessible servers, and reposted by users who can remix and/or repurpose them at any point for their own aims. As cultural objects infused with agency, these images represent a wholly new era of political expression, and they are saturated with moral, ethical and geo-political nuances and force.

To better understand the role of digital-networked images as a site for engaging in a personal 'visual' action, this article analyzes a nude self-portraiture, captured and disseminated online by a young Egyptian woman Aliaa Magda Elmahdy, which during the Egyptian uprisings in 2011 drew profound attention across social media in part because of the nudity it displayed. As an artifact of the visual activism phenomenon, Elmahdy's self-portrait is a prime example of the use of digital-networked images in temporally intentional distribution, and as an instance of political enactment unique to 21 st century. Studying the image also furthers the current scholarship on political implications of selfies and their impact on notions of power, citizenship, democracy, and protest among others. Even though Elmahdy's self-portrait was not captured by a smart phone camera held at arm's length or pointed at a mirror, an attribute commonly detected in a selfie image, her image is typical of a contemporary selfie image. A selfie is primarily a networked self-portrait taken to be disseminated across the Web and social media (Tifentale \& Manovich, 2015). Similarly, Elmahdy took the image of herself for the sole purpose of uploading it on to her blog page and sharing it online.

The method of analysis used here to discuss the implications of social media image activism is twofold: first, it applies semiotic analysis using Barthes' (1980) theoretical concept of the rhetoric of the image which he posits contain three layers of a meaning: linguistic, denoted, and connoted. Examining Elmahdy's visual political expression from a multidisciplinary perspective necessarily leads to inquiries about the meaning of the digitalnetworked image and its reliance on the multiple and immediate textual narratives and visual derivatives that form and circulate in response to it, specifically since they exist outside the image-makers' original intention and control. Most importantly, in their circulation across the Web, derivatives, appropriations and remixes further transform the narrative and meaning of the original image away from the original intent of the image-maker. Because of the dynamic environment in which they func- tion, this analysis of selfie-derived digital activism and its associative texts hereafter posits participatory narrative as a new category of meaning formation in research about the political use of digital-networked images. ${ }^{2}$ Within online communities, participatory narratives arise from evolving conversations that inspires responses that may likewise be contingent upon other mediated, citizen-produced visual byproducts surrounding an image. In short, participatory narratives reflect a dialectic relationship between individuals and digital technology that takes expression across social media.

Given this dialectic environment, this study further imposes sociopolitical analysis using Bennett \& Segerberg's (2012) theory of connective action for understanding personalized politics in the 21st century and Gerbaudo's $(2014,2015)$ framework on how individualized forms of politics are in fact manifestations of new forms of collective identities in the contemporary web. Digital-networked images such as Elmahdy's reveal their capacity to serve as a popular easy-to-personalize action frame through which other participants are then able to channel their own personal stories, interpretations, and histories as part of various collective identities. In effect, interconnected online citizens, or netizens, participate politically by creatively producing, mixing, re-appropriating, and even circulating their own original creations, imbuing them with a particular, personal aesthetic, leading to construction of a collective weness. In doing so, whether purposely or indirectly, they fundamentally alter the framework for political protesting (Gerbaudo, 2015), which has historically been conceived as a centralized, one-to-many or few-to-many on the ground act using a shared and singular approach (Melucci, Keane, \& Mier, 1989; Taylor \& Whittier, 1992).

\section{Analytical Perspectives on Digital-Networked Images as Personal, Political Action}

Using personal digital-networked images to express sociopolitical opinions conveys a different kind of personal presence operating within political discourse than one achieved through textual forms of online communication or, for that matter, through the collective action strategies designed by any political organization. Unlike in the past, when comparatively few individuals with access to the expensive technologies of image making could engage in this powerful form of expression, the increasing ubiquity of mobile and affordable digital cameras, their vastly improved design in the last decade, and the immediacy of social media connecting political geographies and borders allows ordinary citizens around the globe to instantly announce their support or disenchantment with ruling parties or public policy. Digital-networked images have the potential to disrupt even state-imposed political processes through this creative form of visual

\footnotetext{
2 The phrase participatory narrative alludes to Jenkin's (2009) phrase "participatory culture" from the early days of the Internet whereby he brought attention to the participatory qualities of digital media that encouraged communities to creatively and actively interact, collaborate and participate in production of culture and promoted civic engagement.
} 
expression (Gerbaudo, 2015; Kraidy, 2016; Mottahedeh, 2015; Van Zoonen et al., 2010).

In Representing the Unrepresentable, her seminal study of political identity in Iranian cinema, Mottahedeh (2008) justifies her use of Foucault's archeological method as a means to study the reciprocal and ahistorical link between visual texts and political identity. Mottahedeh reasserts Foucault's focus upon "transformations in their specificity" (p. 118) in order to account for discontinuity in the evolution of an idea-or in this discussion, the life of a digital-networked image-this approach also captures the phenomenon of specific, individual intellects expressing political agency in what I deem a poststate sphere using the technology of the digital image. Mottahedeh explains that it is in the moment of confrontation between individual intellect and state intent that transformation, reorganization and reconstitution of meaning production takes place (p. 120). Upending systems of power and knowledge, activist-inspired selfies resituate political power, knowledge and information distribution to within the individual. Reimagining cultural image-artifacts in this way "is a task with global consequences" (p. 120) in that it concomitantly alters our understanding of institutions and technologies themselves.

As professional photographers will attest, selfies also disrupt previous paradigms within the disciplines that frame their cultural acceptance. For both elected officials and disciplinary practitioners, therefore, selfies beg the question "where is this decentering of power taking us and how far?" to which none of us quite know the answer. Nevertheless, in their potent ability to draw public attention away from state or conventional narratives and onto expressions by individuals who are unrepresented, misrepresented and marginalized, digital-networked images of the sort examined here afford power over hegemonic conventions.

Prior to the era of ubiquitous digital communication, the points of entry into protest spaces were primarily facilitated by the organized groups who directed citizens' participation and mobilization within well-defined action frames (Bennett \& Segerberg, 2012, p. 770). The focus of these group-oriented action frames was on building a single collective identity or "the shared definition of a group that derives from its members' common interests, experiences and solidarity" (Taylor \& Whittier, 1992, p. 105). A good example of a collective action frame is street protesters showing solidarity with a cause by marching shoulder-to-shoulder, wearing identically-designed outfits, or carrying posters and placards that the organizations provided for them. By creating a shared sense of identity and "we-ness", collective agents were traditionally organized towards collective action.

The present age of personal, networked communication ushers in a new paradigm for sociopolitical organization centered not on forming a single shared identity but instead on individuals and temporary personalized actions and communication methods (Bennett \& Segerberg, 2012). Affirming the process of individualiza- tion in networked societies, Castells (2004) states that the frames of action in the new context are shaped and reshaped according to the values and needs of individual political actors and "the need and desire for sharing and co-experiencing" (p. 223). Similarly, using the term "connective action" Bennett and Segerberg (2012) examine the impact of the Internet and social media communication technologies on recent sociopolitical movements to argue that citizens' engagement with this emerging form of political action "is more derived through inclusive and diverse large-scale personal expression than through common group or ideological identification" (p. 744). Connective action, according to the authors, enables participants to contribute to a social movement by spreading their content to intra- and interpersonal networks on social media.

Connective action is a useful concept for grasping the role of citizen-produced digital-networked images in sociopolitical movements. Offering an alternative visual model for organization, mobilization, and coordination of participation in the 21st century, the images express their contributors' identities, personalities, and narratives and serve as personalized, visual means of communication. But the strong sense of solidarity and collective we-ness that forms among and between digital activists, particularly in relation or response to selfies and other digital-networked images, which take on a life of their own, reveals that connective action is not sufficient to fully describe contemporary social media movements. As such, Gerbaudo (2015) argues that the social media era ushers in an emergent form of collective identification whereby image rallies and avatar protests, which he refers to as "memetic signifiers", are inherently different from traditional protest and a unified collective identity (p. 928). Enabled by connective actions and practices, Gerbaudo maintains, the networked media bring fragmented online communications and interactions together that form collective identities and highly personalized and transient communities (p. 920). In essence, while digital-networked images allow for self-expression and personalization of protest activity, they lead to new ways of experiencing and constructing collectiveness and group solidarity. These images support the "individualsin-the-group" characteristic of social media protesting as proposed by Milan (2015) wherein the author argues that in the Internet age "the 'collective' is experienced through the 'individual' and the group is the means of collective action, rather than its end" (p. 888).

Nevertheless, the frameworks of connective and collective action do not explain the reasons why among a large pool of digital-networked images only a select number become instrumental in shifting the political tide, even if briefly. Nor does it explain the political implications of these personalized acts of expression circulating on social media. Is it the content of the image that directly or indirectly alters its sociopolitical impact, or the mode of dissemination the image-maker employs? That is, if a digital-networked image is deployed to announce 
one's political beliefs how does it construct meaning such that when it is disseminated it generates new participatory narratives, and to what end?

\section{Digital-Networked Image and Formation of Meaning}

A semiotic analysis of emerging, visual modes of civic engagement is useful in understanding how meaning is communicated in digital-networked images and to what extent they function socio-politically. Within, among and between images, Barthes' (1980) taxonomy for understanding meaning construction offers a tool for studying digital-networked images that are specifically designed to be politically charged. According to Barthes, the three different layers of messages mediated through an image are the denoted or literal message, the connoted or symbolic message, and the linguistic message. He describes the denoted message as literal and straightforward, specifically the representation of a visible object in a defined temporal and physical setting. The connoted message is considered symbolic, a representation of the representation, as it were. Furthermore, the meaning of the connoted message, Barthes (1979) argues, is drawn from "the manner in which the society to a certain extent communicates what it thinks of it" (p. 197). The reading of a photograph is thus solely contingent and dependent on the individual viewing it and the socio-cultural frame through which one decodes its message (p. 206).

Consequently, an image can and must be interpreted in variety of ways simply because connoted signifiers are not created and understood through a single set of historical, social, or cultural codes. Pointing to the plurality and variability of readings among image viewers, Barthes (1980) writes, "The variation in readings is not, however, anarchic; it depends on the different kinds of knowledge-practical, national, cultural, aestheticinvested in the image, and these can be classified and brought into a typology" (p. 280). I propose that a typology of politicized digital-networked images is a necessary foundation for predicting the trajectory of future political agency, which is clearly changing in disruptively innovative ways. The conventions and codes that an imagemaker uses to embed connotations could vary significantly from those the viewer will use to decode the message. Viewers, according to Barthes, interpret the meaning of the images based on their own experiences and their contextual points of view. Any reading of an image therefore varies according to the individual viewing it and the context in which it appears, and each with its own potential, and perhaps immeasurable, force. That force of persuasion embedded within digital-networked images evolves, I would argue, from an inherent agreement between image-makers and their imagined and real viewers about civic autonomy.

Lastly, Barthes defines a linguistic message as a verbal signifier that is provided for better understanding of pictures, for example a caption alongside an image. He argues that while it is within the interrelation of all types of messages that meaning is constructed, it is an image's accompanying text that guides the viewer to a particular interpretation of the photograph. Further, Barthes suggests that images are polysemous; that is, they contain multiple layers of meaning and can be interpreted in many ways (p. 274). The linguistic message controls the meaning in otherwise polysemous images, directing them towards a chosen meaning. The text and image therefore can never be viewed as separate from one another; only together do they communicate meaning.

Barthes analysis helps us to explore the process of meaning formation in digital-networked images in the context of political expression. But while a photograph's meaning has historically been contingent on the intentions of the person who created it and the context under which it was received, the pairing of the medium of photography with instantaneous social media has enabled an even more complex system of meaning in digital-networked images. This duo directly impacts their sociopolitical implications of photographs, offers far greater fluidity in meaning creation, and argues for an expansion of Barthes' taxonomy. To that end, the prolific invention of meaning stemming from digitalnetworked images-dialogic imagery-birthed by autonomous intellects and delivered by ever-expanding technology, has the potential to challenge political control and hegemony.

The online circulation of digital-networked images not only empowers citizens to visually broadcast their political stance beyond geographic and state boundaries, it also enlivens the contextual frame within which a poststate visual expression may be viewed and interpreted. While the images may be randomly sand wiched between other completely unrelated images as an end-users click through offerings on the Web, they do so from an informed cultural perspective, and this guides the reading of each image they encounter. That is to say, the context of the image's viewing is carried within the viewer, and this enables even greater freedom of thought and engagement for individuals on both ends of the image. Likewise, the image itself is imbued with political meaning through its semiotic composition and contextual frame. Image-maker, image, and image viewer all exist in a vastly expanded frame of reference, and this defines a new direction for research in communication and political science, among other disciplines.

Moreover, the easy access to image-making tools and image-sharing platforms, and, importantly, the instantaneous link between these technologies, births continuous and overarching flows of reciprocal narratives and visual derivatives, and their cascading participatory effect further influences the intent, meaning and consequent impact of digital-networked images upon political scenes. So where in earlier times the image taker was a static, privileged entity discriminately producing and sharing an image that could then be the focus of far more localized interpretation (as in print publication), a digitalnetworked image functions indiscriminately in planetary 
swirls of reading and rereading, each time with uncontrolled and decentered interpretative power.

Understanding this phenomenon is far more complex than any single image could elucidate; however, selected, notable examples provide a focus for establishing a method to study this emerging visual-political phenomenon. In this article, I interpret digital-networked images captured and created by Middle Eastern women protestors during the Arab Spring and discuss their political meaning and implications. Because these images represent women's protests against patriarchal and sociopolitical repression, they allow us to examine artifacts of autonomous agency within this political context. Further, they offer a site for study of Web-based feminist expression and political intervention that leads to digital collectivism.

\section{The Selfie of Aliaa Magda Elmahdy}

The 2011 self-published self-portrait, selfie, of Aliaa Elmahdy, a young Egyptian woman, presents an opportunity to analyze the meaning and impact of digitalnetworked images that are intended to partake in civic movements or express political dissent (Figure 1). Elmahdy's nude selfie incorporates artistic and personal forms of 21st century political action in response to the ongoing repression, misogyny, and censorship targeting women in Egypt. Since she posted the image to her newly

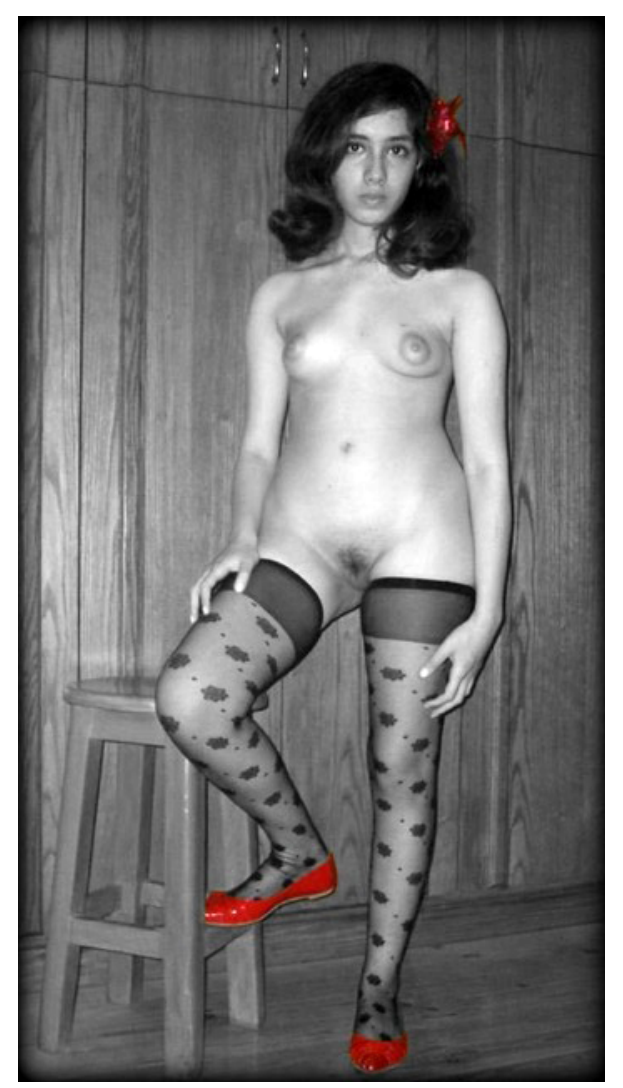

Figure 1. Aliaa Magda Elmahdy nude self-portrait (selfie) published on her blog "A Rebel's Diary", in 2011. launched blog, "A Rebel's Diary”, on October 23, 2011, Elmhady's image has drawn attention across social media platforms and brought over 9 million visitors to her site. On November 17, 2011, ABC News reported that the post received 1.7 million hits since the day it was published, and according to a CNN report, the number of Elmahdy's Twitter followers increased in size from a few hundred to more than 14,000 (Fadel Fahmy, 2011).

In the image, which Elmhady published in black and white, she simply stands in front of the camera wearing only black stockings and a pair of red flat shoes, with a red flower adorning her hair. Resting her right foot on the nearby footstool and her hands casually against her thighs, she confidently looks straight in the camera. Captioning the image, she writes:

Put on trial the artists' models who posed nude for art schools until the early 70s, hide the art books and destroy the nude statues of antiquity, then undress and stand before a mirror and burn your bodies that you despise to forever rid yourselves of your sexual hang-ups before you direct your humiliation and chauvinism and dare to try to deny me my freedom of expression.

Elmahdy's public nudity appears to be a declaration of her rights as a female Egyptian citizen. As the accompanying text suggests, her depiction of nudity is an overt demand to end the existing sexism, repression, and violence against Egyptian women, particularly in view of the rising influence of the Islamist party in her country's politics.

Looking at Elmahdy's self-portrait, the denoted messages, or visible signifiers, are easily identifiable: a nude Middle-Eastern woman, her red hair flower, red flat shoes, the footstool, and a room that appears to be a bedroom space. These denoted messages literally translate to "a naked woman standing in a bedroom". While the nudity may raise curiosity in the viewers' mind, with its similarity to millions of other female nudes in the online space, Elmahdy's digital-networked image looks like a familiar non-coded, nude self-portrait. However, as Barthes affirms, no image can be purely denoted. The meaning of an image is extracted through connoted messages hidden within the photographic images. Image treatment or stylistic interventions of composition, lighting, coloring, and juxtaposition provide connoted layers of meaning.

Yet, upon closer reading amateurism becomes apparent in the photograph. The arrangement of the visual elements does not follow the conventions of professional photography in terms of composition, focus, lighting, or framing; the background's texture and lines are distracting and the cropping of the image is too tight, especially towards the bottom of the photograph. The oncamera flash has created a harsh, unnatural shadow contour around the body, which is another common feature of non-professional photographs. 
Despite its amateur composition, Elmahdy's selfportrait is nevertheless calculated and planned. Specifically, her choice of red shoes and a red flower in her hair, deliberately juxtaposed against a monochromatic backdrop, and the irony implied in Elmahdy's nonerotic pose yet titillating floral stockings, stir curiosity. Elmahdy's careful use of red within the monochromatic scene heightens the impact of the image, separating it from other color self-portrait snapshots-and other sexualized pornographic images-found on the Web. The sparing use of red within the monochromatic tone also directs the viewer's gaze through the contours of Elmahdy's naked figure, drawing the eyes from the red flower to the red shoes and away from her exposed private areas in the center of the composition. As a result, the image emphasizes her censored and forgotten femininity, without being overtly sexual.

Even though the tight stockings suggest sexuality, and her nakedness implies vulnerability, Elmahdy's piercing gaze confronts the viewer with a sense of selfconfidence that is very different from the self-effacing demeanor enforced upon Muslim women. On the contrary, Elmahdy is neither friendly nor inviting. Appearing unconcerned about her nakedness, which has now been seen repeatedly on the Web and will persist for an indeterminate time, Elmahdy's visage lacks any trace of emotion, whether happiness, coquetry, sadness, or even anger. In her nudity, she re-inscribes externally-imposed definitions of her own personhood against Arab and Islamic definitions of privacy, womanhood, modesty, and respectability by boldly refusing to hide any aspect of her sexuality and femininity.

\section{Digital-Networked Image as Rebel's Diary}

Taking the selfie against a wood-paneled wall that appears to be in a bedroom ${ }^{3}$ - a familiar domestic domainElmahdy knowingly broadcasts her private body and private sphere publicly on social media. Posting the image on social media, she leaves the confines of the domestic space and goes outside, all by herself, to demand attention to her female existence and her neglected needs. Bearing in mind that in most Muslim countries women are assigned to the domestic sphere, and that women's presence in society is usually chaperoned by patriarchal guardianship (father, brother, or husband), Elmahdy's selfie represents an extreme act of transgression and rebellion or as Kraidy (2016) puts it a "radical mode of creative insurgency" (p. 161). Through the process of self-representation, she constructs a political subjectivity, reclaims control over her body, and breaks away from the social constraints and traditional Arab mores and customs about women's seclusion from the public. Not only did her choice to appear undressed in front of camera indicate female promiscuity in the Arab culture, but Elmahdy's red hair flower and tight lace stockings demonstrate rebellion even against the idea of female modesty.
But the meaning of Elmahdy's digital-networked image does not clearly reveal itself until the viewer pairs the image with its textual accompaniment or linguistic message. The written text, which functions in the form of caption, username, and blog name, elucidates and further contextualizes additional meaning, and provides a set of interpretative schemes to better understand the photograph. In stark contrast to her peaceful pose and seemingly indifferent gaze, Elmahdy's written text is violent and confrontational. It sets out a sense of anger and destruction that is not visible in the image. Even though the selfie conveys her revolt to reclaim her femininity within a passive pose, her near-manifesto caption is filled with active verbs that shame the reader for the injustice, humiliation, negligence, and ignorance imposed upon Egyptian women. Writing, "put on trial the artists' models...hide the books...destroy the nude statues of antiquity...burn your bodies" she demands an end to the misogyny that she and other Egyptian women have endured for centuries. By including a verbal caption, Elmahdy forthrightly asserts how she wants her body to be read by the unending, global and reactionary audience she clearly imagined and predicted.

Elmahdy's aesthetic choices, the accompanying text, and her use of the Web as a medium of dissemination indicate a purposeful visual and political construction, blurring the line between photography and political insurgency. In that regard, Elmahdy's conceptual approach and execution closely resemble the style and conventions of several contemporary feminist artists who embraced female nudity and the female body as a subject of continuous self-exploration. These similarities invoke another layer of political meaning into Elmahdy's deceptively personal selfie. Specifically, political selfportraiture has been explored creatively by feminist artist Hannah Wilke, who, through a series of nude selfportrait still images and videos, defined and redefined womanhood outside of the social norm established by the art world in particular and by mass media generally. Wilke frequently presented her own fully- or partiallynaked body, in front of the camera using her own images in creative political expression.

For example, in her provocative photo series IntraVenus, Wilke (1992) confronts the viewer with a forbidden subject: her nude female body while undergoing chemotherapy as she battles lymphoma drawing attention to the political implications of cancer and of women's experience of it. In one of the self-portraits, she stands against a white wall naked and facing the camera. Wilke's body appears indisposed, vulnerable, and weak, but her pose conveys conviction and energy. Posing like a high fashion model, she places one hand on her hip and the other on her stomach, and bends her right knee ina pose used in marketing and modeling to make the hips appear slimmer. She directs her gaze towards the camera, she presents the viewer an unseen state of the feminine body; instead of high heels, she's in white house

\footnotetext{
${ }^{3}$ She later wrote on Twitter that she took the image at her parents' house.
} 
slippers. With the simple composition and the flash illumination reflected on Wilke's body, the photograph first appears candid, transparently denoting cancer and approaching death.

Wilke's photographs present layers of meaning and the bold image of a body ravaged by cancer is not only denotative, but also connotes a political statement left for the reader to impose upon it. Wilke's boldly nude artistry is both distant enough from viewers to keep her safe from harm and at the same time penetratingly disruptive for viewers because it provokes cultural norms revealing a contradictory view of the feminine body, one that challenges mainstream capitalistic ideals of femininity, feminine beauty, and youth in the Western culture. Wilke's photograph is not a snapshot capturing an instant and candid moment but a personal-is-political statement rendered in photography. This may be why it became the method used by Aliaa Magda Elmahdy. In like manner, by posing nude in front of the camera Elmahdy unveils female sexuality that's been tangled with repressive social codes of modesty and morals. She uses her unclothed body to reveal the censored sexuality and suppressed voices of Egyptian women she strives to reclaim.

Another photograph from the early feminist art movement resembling Elmahdy's is the infamous selfportrait of Lynda Benglis, which appeared as an ad page in the November, 1974, issue of Artforum. Benglis spent $\$ 3,000$ to buy the ad space-a significant amount for the time-to advertise for her upcoming exhibition at the Paula Cooper Gallery in New York City. In the ad, she poses naked holding a latex dildo in her right hand to symbolically represent the power associated with masculinity (Ratcliff, n.d.). By publishing an image of herself as a phallic woman in a reputable and popular art magazine, Benglis mocks the male domination and overrepresentation in the art world and rebels against underrepresentation of women. Like Benglis, Elmahdy breaks the rules by inserting herself in a male-dominated public discourse.

\section{Vulgarity as Digital Artifact: Online Political Reactions}

Nonetheless, even if Elmahdy could afford to buy an expensive ad space, she could never appear nude in any print or broadcasting media in the Middle East. The cultural and religious laws strictly prohibit Muslim women from appearing in public without the Islamic dress code and in parts of the region women are punished for not complying with the prescribed dress code. As an Egyptian woman with unconventional ideas, Elmahdy successfully defies public restrictions by using the Internet as her method of communication. Publishing her selfie online granted her access to an audience much larger than the number of subscribers to any magazine or local TV station. Unlike Benglis, whose audience was limited to Artforum subscribers, or Wilke, whose work was seldom widely published outside the limited spaces of galleries and museums and hence generally remained within the small circle of art enthusiasts, Elmahdy's image reached Internet users around the world and her story was covered by major news media outlets. Thus, through online circulation, Elmahdy's work became more widely known among the general public than the other acclaimed artworks. The distribution of her digital-networked image transformed an act of political insurgency into an iconoclasm, a post-state personalized political artifact that enabled Elmahdy to participate in social uprising on a global level, without physically protesting on the street or putting herself in danger for appearing nude on a public street.

This perhaps contributes to why Elmahdy's online declaration of political position was subjected her to risks or adverse reaction. Indeed, the backlash against the online circulation of Elmahdy's photograph was such that even secular, liberal opposition groups immediately and publicly rejected any affiliation with Elmahdy, fearing that her radical behavior could potentially damage their reputation and popularity among Egyptian voters in the upcoming parliamentary election. On Twitter, Egyptian liberals expressed concerns that the conservative Islamists would blame the party for Elmahdy's action: "They're gonna throw it all on liberals and seculars [sic]" (AliHgrs, 2011).

With the image circulating the Web and on the media, the Egyptian opposition felt the need to immediately disavow any connection to Elmahdy, especially since she described herself as a secular, liberal feminist Egyptian on her blog. On November 17, 2011, the New York Times reported that in an interview with the Pan-Arab news channel Al Arabiya, Tarek al-Kholi, the spokesperson for the liberal activist group "April 6th Youth Movement" denied that Elmahdy was ever a member of the group, saying, "the movement does not have any members who engage in such behavior" (Stack \& Kirkpatricknov, 2011). ${ }^{4}$

An Egyptian political group to publicly renouncing an unknown feminist blogger ${ }^{5}$ reveals that by releasing the unconventional digital-networked image on social media, Elmahdy posed a threat to the opposition group's collective identity as well as political control of her female identity. Instead of adhering to the organization's action frameworks, she independently and deliberately constructed her own political identity and inhabited the globalized political space in a radically individualist way. What's more, the Egyptian opposition wasn't the only group denouncing Elmahdy's nude selfie. Many other viewers from across the Arab world also equated the self-portrait with impropriety and even pornography. For instance, labeling the selfie

\footnotetext{
4 "April 6th Youth Movement" was a major player in the revolt that unseated Egypt's President Mubarak and a group in which, according to several media outlets, Elmahdy claimed membership (Stack \& Kirkpatricknov, 2011).

${ }^{5}$ This level of attention is astonishing considering that Elmahdy wasn't an established blogger in the otherwise highly active Egyptian blogosphere. In fact, she had only published one other post prior to the October 23 entry, compiled on September 25, 2011.
} 
as obscene and appalling, a Twitter user who describes himself as an evolving orthodox Muslim and the founder of http://MuslimMatters.org denounced and ridiculed Elmahdy by tweeting, "\#NudePhotoRevolutionary or \#NudePhotoDevaluationary? Egyptians rose to get rid of Mubarak, not to open a local chapter of Play(Arab)boy" (Ahmad, 2011). Another Twitter user reflected on Elmahdy's image by calling it "a disgrace to Egyptian women" (Maryam, 2011). Aside from attacking Elmahdy's character, many users dismissed her image as a political act and questioned its sociopolitical impact, writing comments such as "stripping down for a 'cause' is absolute bull shit" (Noorhan, 2011).

The dismissing tweets manifest that by situating a woman's private moment within Egypt's public discourse and by disseminating it publicly and globally, Elmahdy's nude selfie committed a violation of the codes of conduct that women, even women outside of Egypt, are subject to. By claiming her own body and using it as a way to highlight cultural conventions that suffocated the rights of women and perpetuated chauvinism, she committed unforgivable or useless wrongdoing in the eyes of some of the viewers. In other words, she "acted like a woman unbridled by male authority" (Kraidy, 2016, p. 166). Elmahdy's selfie was an act of public transgression against patriarchal jurisdiction, even within the leftist political organization. With the combination of the connoted, denoted, and linguistic messages authenticating her gender, Egyptian background, and audacious self-assertion, Elmahdy selfie and manifesto disrupted the cultural expectations of how women, even liberal women, must behave. They evoked "an explosive mix of sexuality, politics, identity, and violence" through which she "came to represent Egypt, or to be more precise an anti-Egypt" (Kraidy, 2016, p. 167). As a result, her image of unfamiliar, non-submissive, and unruly Egyptian woman represented a challenge to culturally-normative gender and sexuality categories inside and outside Egypt.

The negative reaction to Elmahdy's self-portrait is reminiscent of the reaction Benglis received after her ad was published in Artforum. After its release, several Artforum associate editors announced their dismay about Benglis's "vulgar" actions by publishing a letter to Artforum's editor in chief, and many feminist advocates spoke publicly against the work calling it offensive and a perpetuation of female objectification and male gaze (Poundstone, 2011). Considering the sheer amount of female nudity that fills the pages of magazines and walls of art galleries and museums, not to mention the praise those works receive for their artistic merit, the criticism against Benglis and Elmahdy is paradoxical. It indicates misunderstanding and rejection of both the visual, artistic display of the female body by women artists and the inherent autonomy of their political expression: Whereas naked female bodies in high art are culturally registered as forms of aesthetic experience, these nude self-designed acts in popular culture are identified as profane and obscene.

In her book The Female Nude: Art, Obscenity and Sexuality, Lynda Nead (1992) argues that the cultural distinction in responding to female nudity is based on the type of cultural consumption, less dependent upon the content of the image than on how, where, and in what context the image is seen and who has access to it ( $p$. 86). She adds, "Within the gallery, the female body is displayed as a symbol of legitimate public culture; within the adult bookstore, its display becomes a sign of the covert and irregular aspects of cultural consumption" ( $p$. 101). Whereas venues such as adult bookstores or video rooms provide a space that encourages and elicits physical reactions to the image, the gallery provides a public, contemplative, and controlled physical environment for consumption of nudity under the context of high art. Nead therefore separates the depiction of female nude in art and pornography in terms of quality, ownership, and access.

An important point to be drawn from Nead's analysis is that once removed from the protected realm of art, or from the thinking space of art galleries and museums, the image of the female nude is commonly viewed by society as a visual manifestation of promiscuity and moral corruption, subjected to derogatory labels such as indecent, shameful, and pornographic. Such inconsistency in interpreting and responding to the human female form, particularly when it is self-presented, explains the negative reaction to the published images of Benglis and Elmahdy, by those who would condemn such expression as immoral, indecent, and even unartistic. ${ }^{6}$

While online forums, tweets, and comments mostly consisted of opposing views against Elmahdy, she did receive some level of support from individuals and groups who viewed the image as an empowering act of resistance against patriarchal control. For instance, a Kuwaiti Twitter user (Alshamri, 2011) applauded Elmahdy for breaking social taboos and reclaiming femininity and the female body as a human subject instead of a shameful sexual object that needs to be censored. In general, depending on the viewers' beliefs about female public nudity and their definition of the word revolution, corresponding comments demonstrated diverse and contradictory opinions.

\section{Polysemous Digital-Networked Images: Interpreting the Interpreter}

The conflicting reactions to Elmahdy's selfie stem from the image's polysemous nature, its capacity for multiple meanings. Considering that interpreting connoted messages is dependent upon the contextual, historical, and social convictions the viewer applies in viewing the image (Barthes, 1979, p. 206), by bringing varying degrees of knowledge, experience, and history, Elmahdy's local

\footnotetext{
${ }^{6}$ For instance on November 12, 2011, Amr Abed @Anoutsider wrote “@TheMiinz i totally agree with everything you said! there is nothing artistic about it and it's kinda offensive tbh \#NudePhotoRevolutionary".
} 
and global viewers each had a distinct reading of the image, independent of Elmahdy's own sociopolitical vision as expressed even in her accompanying caption.

When it comes to digital-networked images, the relationship between the text and the image is, in fact, complex, and it influences the process of meaning formation immensely. More importantly, the emerging dynamic between the text and digital-networked images further complicates the Barthesian framework for the linguistic message and its two functions: anchorage and relay. Barthes (1980) describes anchorage as "the most common function of the linguistic message", textual information provided by the image-maker that directs the viewer toward a particular reading of the image (p. 275). Relay, on the other hand, works alongside the image, expanding on the meaning of the image to something other than could be understood from the image alone. In relay, text and image "stand in a complementary relationship" and meaning is created through the interrelation between the image and text and text and image (p. 275). Elmahdy's manifesto functions as relay, advancing the image and supplying information that is not found within it. Upon reading the text, the viewer realizes Elmahdy's motives, her Egyptian background, and her demands as an Egyptian woman within the civic uprisings in the country.

A relay functions somewhat differently in interpretations of digital-networked images disseminated in social media, however. Due to the nature of networked communications, images generally disseminate around the Web in the form of online comments, blog posts, or micro-reports embedded as links alongside personal notes or comments about the content. These additional layers of accompanying text amplify the function of relay as a gateway to the image content by inscribing viewers' interpretation on the image as well. (Even though many sites, including Twitter, now have the capacity to directly embed images, sharing images as text-based hyperlinks remains a common practice-especially since link-sharing across platforms is still widespread). The additional circulation of textual information further complicates the meaning of the image, resulting in partiality and preconceptions about the content depicted (Kasra, Shen, \& O'Brien, 2016). The endless, perhaps immeasurable, circulation of information on the Web not only makes the image available to those who come from different backgrounds, speak different languages, and are therefore accustomed to different cultures and ideologies, it also performs as the focal point for an evolving participatory narrative.

Depending on the viewers' beliefs about female public nudity and their definition of the word revolution, corresponding comments on Twitter demonstrate diverse and contradictory opinions in support or condemnation of Elmahdy's selfie. The meaning of Elmahdy's image was therefore equally dependent on the multiple and immediate comments that circulated on the Web in response to it then and ever afterward.

For example, the story about the self-portrait first broke on Twitter by a popular Egyptian human rights activist and blogger, Ahmed Awadalla, who had close to 10,000 followers. $^{7}$ Cautious about revealing Elmahdy's identity, and fearing for her safety, Awadalla did not share a link to the blog post and the original image, nor did he identify Elmahdy's Twitter username. Instead he wrote, "A feminist \#Jan25 revolutionary posted her nude photo on the Internet to express her freedom" (Awadalla, 2011a). His careful choice of terms such as feminist, revolutionary, express, and freedom, defined a context through which his Twitter followers preemptively interpreted Elmahdy's activism prior to witnessing the image. Awadalla's description could have influenced viewers' reading and helped to frame their response to it.

As follow up, Awadalla later posted on Twitter: "So to sum up, some see \#NudePhotoRevolutionary as progressive \& brave, others see Harem, 3eeb [sic] \& harms revolutionaries image! Any comments?" (Awadalla, 2011b). Doing so, Awadalla additionally framed Elmahdy's selfie in a way that viewers were invited to comment on her personal act-her decision to appear naked in front of the camera-without having to witness the image itself. Even the Twitter hashtag \#NudePhotoRevolutionary, which Awadalla created to direct the forthcoming traffic in response to the photograph, provoked controversial reactions among the viewers due to the pairing of the words "nude" and "revolutionary". 8

\section{Derivatives, Re-Appropriations and the Political Force of Participatory Narratives}

Digital-networked images cultivate autonomous and personalized approaches to citizen participation and enable viewers to shape and reshape the meaning of these visual actions by embedding their own stories, viewpoints, values, and histories into the subsequent narratives. The meaning of the digital-networked image thus becomes tightly related to its derivatives and re-appropriations that expand the scope of its sociopolitical reach globally and exponentially. The emergence of the digitalnetworked image thereby sets forth the participatory narrative as a new and additional category of meaning expansive of the Barthesian semiotic model put forward in "The Rhetoric of the Image" (linguistic, connoted, and denoted) (1980). This kind of poststructuralist participatory narrative conveys the evolving textual narratives and visual derivatives that social media dwellers disseminate in response to a digital-networked image. The meaning of the 21st century image is therefore not only depen-

\footnotetext{
${ }^{7}$ Writing mostly about issues surrounding human rights, gender, health, and sexuality, on his blog space "Rebel with a Cause", Awadalla describes his writings as "an attempt to explore not-so-often-discussed taboo issues in Egypt".

${ }^{8}$ Twitter hashtags allow users to form communities of people interested in the same topic by making it easier for them to find and share related information.
} 
dent upon what the content depicts (its indexicality) or the indexation it provides. Rather, it arises from, or is contingent upon, the evolving social construction it inspires for as long as the image exists and is distributed.

Elmahdy's selfie offered as an easy-to-personalize connective action that other participants replicated, appropriated, or adapted when voicing their own opinions. With easier access to image-making and imagesharing technologies, viewers responded to the message conveyed in her nude selfie by creating corresponding remixed visual content ranging from selfies to other visual meaning-laden derivatives. Functioning as an everchanging unifying symbol, Elmahdy's nude selfie generated a sense of collective identity among many participants. Using the topical hashtag \#NudePhotoRevolutionary on Twitter and Instagram, or submitting their images to Elmahdy's Facebook page, supporters co-create and perpetuate the discourse by building upon and advancing the meaning of the nude selfie and its associated narratives. (Elmahdy began showcasing these images on her blog and in her Facebook album and titled them "Nude Art"). For instance, a contributor remixed a close-up of Elmahdy's face upon the historical photo-based work of the established feminist artist Barbara Kruger (1989). The remixed composition reminds the viewer that women's social struggle against power, patriarchy, and male control has been an ongoing battle. Kruger created the original artwork for a 1989 march in Washington, DC, in support of women's reproductive rights and particularly their right to abortion.

Kruger's work depicts a black and white imagery of a woman's face vertically split in two halves, combined with bold, red blocks of text running across the composition. Dividing the image into two parts, she keeps the right half in positive while she inverts the other half into a negative image. The play with positive and negative spaces is to bring attention to the binary oppositions

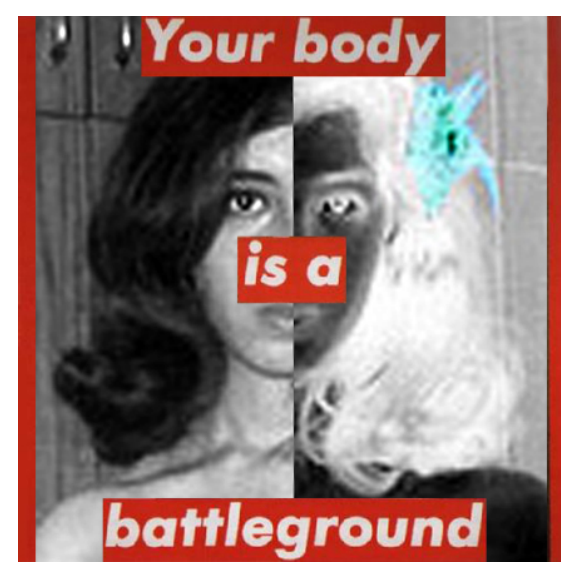

Figure 2. Composition submitted to Elmahdy's blog "A Rebel's Diary" by online supporters who remixed a closeup of Elmahdy's face upon the historical photo-based work of the established artist Barbara Kruger (2011). around concepts such as good/bad, whore/Madonna, private/public existing and operating in society. By writing the phrase "Your Body is a Battleground" in bold red font across the black and white composition, Kruger speaks about women's constant struggle over their social rights, and men's ongoing control over women's bodies and reproductive rights as a way to sustain patriarchy. Cleverly, the remix version replaces the female portrait Kruger used in the original composition with that of Elmahdy while keeping the other parts intact (Figure 2). In many ways the remix demonstrates how women's issues are universal and not limited to certain regions or a certain period, and by doing so expands on the message conveyed by Elmahdy's image alone.

Other contributors reenacted Elmahdy's self-portrait to show solidarity and to re-contextualize the image within their own social, political, and cultural circumstances. Participants in these visual campaigns intertwined Elmahdy's rebellious approach into their own unique statements. Enacting the scene, they retold the story of oppression based on their personal experience. For example, Israeli activist Or Tepler created a Facebook event inviting women, regardless of their religion or sexual orientation, to show their solidarity "in a non-violent and legitimate way" to a woman "who is just like usyoung, ambitious, full of dreams and evidently has a developed sense of humor" (Kais, 2011). Dozens of women responded to Tepler's call by posing nude in a group image, holding signs that read, "Love without Limits", and "Homage to Aliaa Elmahdy. Sisters in Israel". The digitalnetworked image was later covered by news media reports around the world (Figure 3 ).

Similarly, to honor Elmahdy and in celebration of International Women's Day, Iranian-born secular-feminist and activist Maryam Namazie (2011) published her "Nude Photo Revolutionaries Calendar" (Figure 4). Like Tepler, Namazie (2011) launched an online image-based protest in solidarity with Elmahdy inviting women from around the world to post nude self-portraits on Twitter under the hashtag \#NudePhotoRevolutionary. The accumulation of these images indicates that Elmahdy's personalized political action resonated with others with shared ideology even outside Egypt, and inspired other women to individualize her political act using imagery as a way to come together and transmit their own message.

The user-generated content responding to Elmahdy's digital-networked image varied in style and approach; their own dissemination of it on social media broadened its reach, as well. Gradually, Elmahdy's selfie began functioning less as a symbol of an Egyptian woman on a personal quest to free herself from social constraints, and more as part of an ongoing and overarching narrative compiled of the viewers' own stories, experiences, opinions, and participatory media content.

While supporters used participatory visual derivatives to endorse Elmahdy for raising awareness against misogynistic censorship, viewers with opposing viewpoints also used digital-networked images to scoff at 


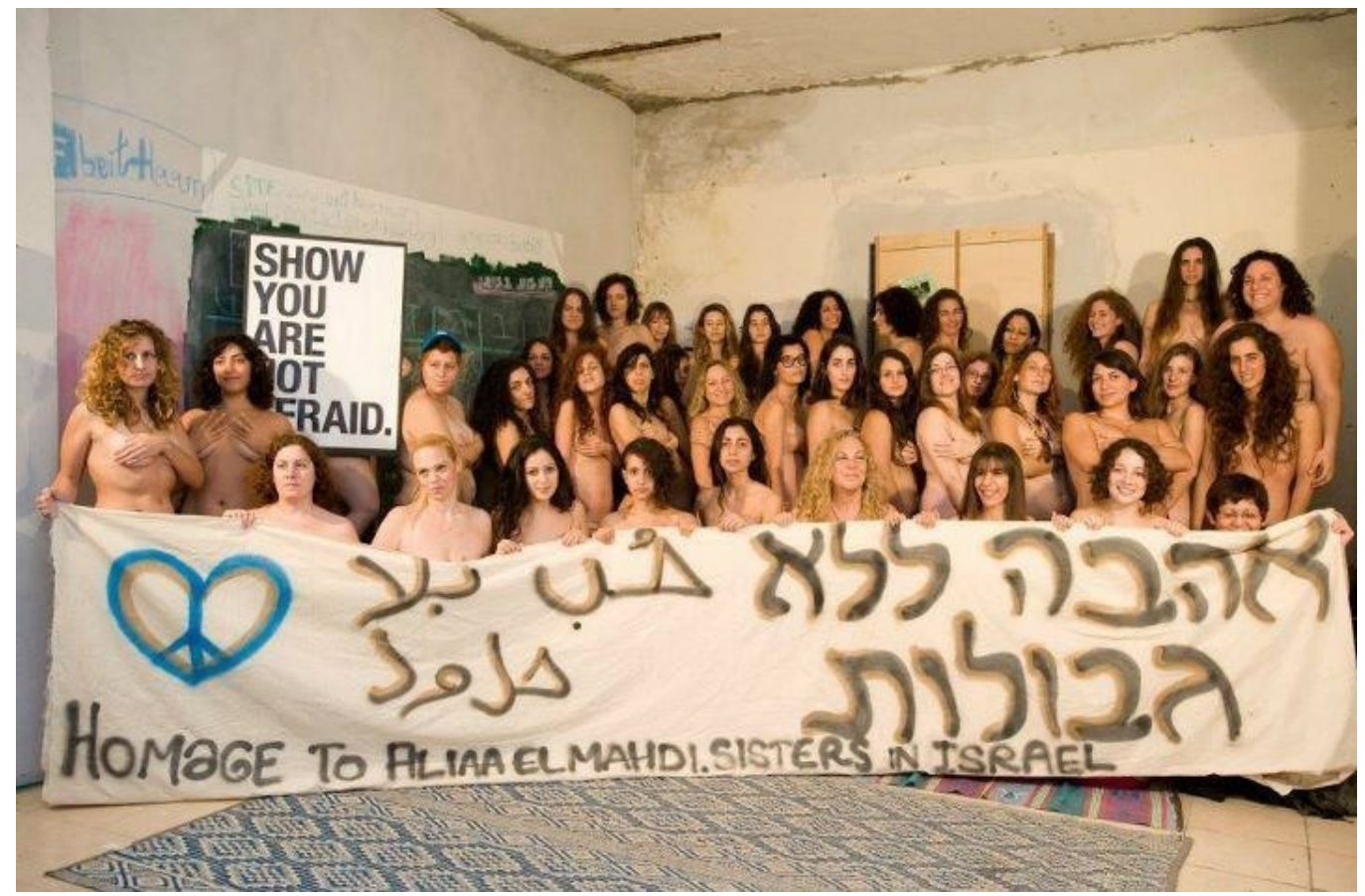

Figure 3. Israeli women posing nude "Love without Limits" and "Homage to Aliaa Elmahdy Sisters in Israel" (2011).

her and divert her message. In effect, they used the same participatory tool and approach the supporters used to endorse Elmahdy in order to mock and reject her.

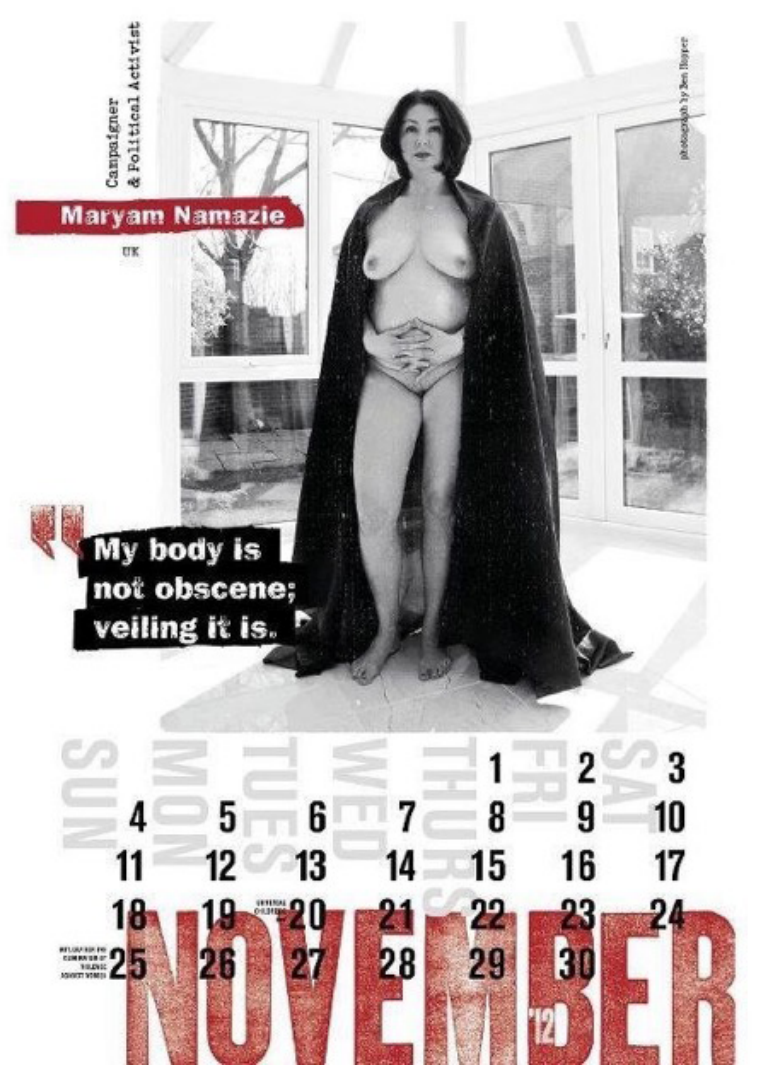

Figure 4. Secular-Feminist Maryam Namazie in her "Nude Photo Revolutionaries Calendar" published in support of Elmahdy (2011).
For instance, in late November, 2011, reports surfaced around the Web that Elmahdy has been beaten in Cairo's Tahrir Square where demonstrators had been rallying against the Egyptian regime for months. The reports even referred to a YouTube video clip that showed a young female protester being pushed and beaten by an angry crowd (Taghyer, 2011) (Figure 5). Despite the fact that the video never showed a close up of the mistreated woman, and therefore made it impossible to identify her as Elmahdy, the false report scattered around the Web very quickly (Mezzofiore, 2011). Even after Elmahdy announced in an interview that she was actually in hiding and was not in Tahrir Square during that incident, the rumor kept circulating, generating especially furious reactions (CyberDissidents, 2011).

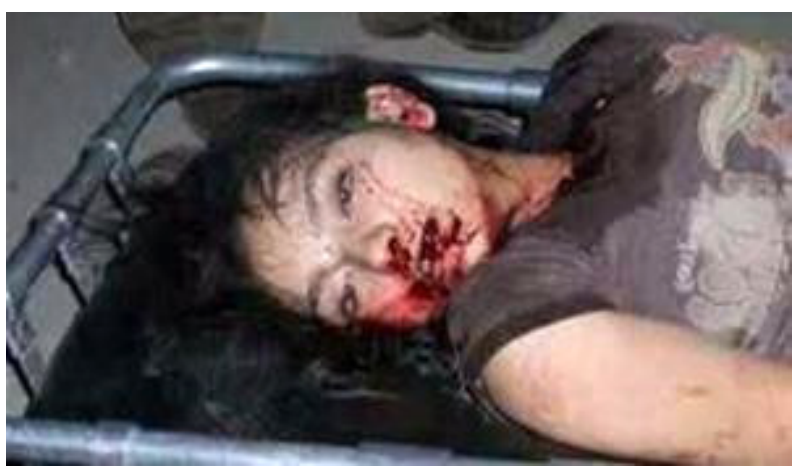

Figure 5. A falsely attributed image that appears to depict a deceased woman bearing a resemblance to Aliaa Elmahdy. False rumors about Elmahdy's death continued to spread online supported in part by this image, December, 2011. Source: Unknown. 
In a different incident in December, 2011, two soonto-be disputed images of Elmahdy surfaced on Twitter. They both depicted a medium shot of a woman from the chest up lying on a hospital stretcher with her mouth and neck covered in blood. While the woman in the picture bore a resemblance to Elmahdy, the low quality of the images and the blood on the woman's face made it impossible to identify her. Nonetheless the two images continued to spread online with captions and comments such as "Aliaa Elmahdy dead" or "Aliaa Elmahdy killed", creating passionate debates among those who either believed she deserved death for inciting indecency and insulting Islam, and those who used the pictures to condemn the Egyptian government and Islamic practices. ${ }^{9}$

\section{Conclusion}

Analyzing Elmahdy's 2011 politically-infused selfie reveals a new means through which underrepresented minorities may find a voice on a global scale, and in spite of repressive state laws and sovereign jurisdictions. Elmahdy's self-possession and image-based, defiant selfexpression starkly highlights the autonomous and participatory nature of the digital-network image and its role in perpetuating activism. It also reveals the means by which the digital-networked image inspires endless permutations of new image expressions and re-appropriations in the viewers.

The use of digital-networked imagery enabled Elmahdy and her supporters to raise their political voice amidst heated turmoil in Egypt. Their image-based political action challenged their national identity and constituted a great threat to patriarchal jurisdiction. Whether Elmahdy knowingly established her non-state political agency using a selfie or whether she expected such level of support or backlash against her photographic action will forever remain unknown. What's certain, however, is that the digital-networked image that the world witnessed in the fall of 2011 neither corresponds with the stereotyped depictions of Egyptian women by the Western media, nor fits the model of the ideal woman promoted by the Arab world. The woman represented in that digital-networked image was anything but closeted, silent, subordinate or submissive, and her appearance and determination appeared to be far from the Islamic ideal of female identity. Digital-networked images enabled Elmahdy, and later her global supporters, to unfold a new era of feminine identity and political participation in the Arab world, providing them with a means of resistance against well-established cultural and social inequalities. Albeit like most social media movements this resistance was transient and infused with consequences and risks. In fact, facing death threats from Islamist extremists for disgracing Islam and Muslims, Elmahdy eventually was forced to flee Egypt and live in exile (Würger, 2013).

\section{Acknowledgments}

My special thanks to the editors and anonymous reviewers who provided valuable comments on earlier drafts of this manuscript.

\section{Conflict of Interests}

The author declares no conflict of interests.

\section{References}

Ahmad [amadshk]. (2011, November 14). \#NudePhotoRevolutionary or \#NudePhotoDevaluationary? Egyptians rose to get rid of Mubarak, not to open a local chapter of Play(Arab)boy. Twitter. Retrieved from https://twitter.com/amadshk/status/136096147461 767168

AliHgrs [AliHgrs]. (2011, November 12). Let's just hope salafi sheikhs don't get word of this [sic]. They're gonna throw it all on liberals and seculars \#NudePhotoRevolutionary [sic]. Twitter. Retrieved from https://twitter.com/AliHgrs/status/13537505698448 9984

Alshamri, A. [abrards]. (2011, November 11). @3awadalla I think she really is brave. Nudity is natural and she's sending a message: Abandon past notions of nudity being shameful. Twitter. Retrieved from https://twitter.com/abrards/status/13516134 0670115840

Amr Abed [Anoutsider]. (2011, November 12). @TheMiinz i totally agree with everything you said! there is nothing artistic about it and it's kinda offensive tbh \#NudePhotoRevolutionary. Twitter. Retrieved from https://twitter.com/Anoutsider/status/13537238484 7925248

Awadalla, A. [3awadalla]. (2011a, November 11). A feminist \#Jan25 revolutionary posted her nude photo on the Internet to express her freedoM. Twitter. Retrieved from https://twitter.com/3awadalla/status/ 135158785529479169

Awadalla, A. [3awadalla]. (2011b, November 11). So to sum up, some see \#NudePhotoRevolutionary as progressive \& brave, others see Harem, 3eeb [sic] \& harms revolutionaries image! Any comments? Twitter. Retrieved from https://twitter.com/3awadalla/ status/135172927233605632

Barthes, R. (1979). The photographic message. In S. Sontag (Ed.), A Barthes reader (pp. 194-210). New York, NY: Hill and Wang.

Barthes, R. (1980). Rhetoric of the image. In A. Trachtenberg (Ed.), Classic essays on photography (pp. 269285). New Haven, CT: Leete's Island.

Benglis, L. (1974). Artforum ad. 1974. Feldman Gallery. Retrieved from http://feldmangallery.com/media/ have\%20we\%20met\%20before/artforum-01.jpg

\footnotetext{
${ }^{9}$ See discussion "Aliaa Magda Elmahdy being beaten in Egypt" on Global Secular Humanist Movement (2011) Facebook page: https://www.facebook. com/GSHMP/posts/198615276888397
} 
Bennett, L. W., \& Segerberg, A. (2012). The logic of connective action: Digital media and the personalization of contentious politics. Information, Communication \& Society, 15(5), 739-768.

Castells, M. (2004). Why networks matter. In H. McCarthy, P. Miller, \& P. Skidmore (Eds.), Network logic: Who governs in an interconnected world? (pp. 22124). London: Demos.

CyberDissidents. (2011, November 30). Exclusive interview with Aliaa Elmahdy. CyberDissidents. Retrieved from http://cyberdissidents.s3-website-us-east-1. amazonaws.com/bin/content75fe.html?|D=946\&q= $1 \& s=3$

Fadel Fahmy, M. (2011, November 19). Egyptian blogger Aliaa Elmahdy: Why I posed naked. CNN. Retrieved from http://edition.cnn.com/2011/11/19/ world/meast/nude-blogger-aliaa-magda-elmahdy/ index.html

Gerbaudo, P. (2014). The persistence of collectivity in digital protest. Information, Communication \& Society, 17(2), 264-268.

Gerbaudo, P. (2015). Protest avatars as memetic signifiers: Political profile pictures and the construction of collective identity on social media in the 2011 protest wave. Information, Communication \& Society, 18(8), 916-929. doi:10.1080/1369118X.2015.1043316

Jenkins, H. (2009). Confronting the challenges of participatory culture: Media education for the 21st century. Cambridge, MA: The MIT Press.

Kais, R. (2011, November 20). Israelis strip in support of Egypt blogger. ynetnews.com. Retrieved from http://www.ynetnews.com/articles/0,7340,L-415034 4,00.html

Kasra, M. (2017). Vigilantism, public shaming, and social media hegemony: The role of digital-networked images in humiliation and sociopolitical control. The Communication Review. doi:10.1080/ 10714421.2017.1343068

Kasra, M., Shen, C., \& O'Brien, F. (2016). Seeing is believing: Do people fail to identify fake images on the web? Paper presented at the 17th Annual Conference of the Association of Internet Researchers (AoIR 2016), Berlin, Germany.

Kraidy, M. M. (2016). The naked blogger of Cairo: Creative insurgency in the Arab world. Cambridge, MA: Harvard University Press.

Kruger, B. (1989). Untitled (your body is a battleground). The Broad. Retrieved from http://www. thebroad.org/art/barbara-kruger/untitled-your-body -battleground

Kuntsman, A. (Ed.). (2016). Selfie citizenship (1st ed.). Cham: Springer International Publishing.

Maryam [MaryamArafar]. (2011, November 12). What a disgrace to Egyptian women. This is not bravery. \#NudePhotoRevolutionary. Twitter. Retrieved from https://twitter.com

Melucci, A., Keane, J., \& Mier, P. (1989). Nomads of the present: Social movements and individual needs in contemporary society. Philadelphia, PA: Temple University Press.

Mezzofiore, G. (2011, November 28). Aliaa Magda Elmahdy, nude blogger, reported beaten up in Tahrir Square. International Business Times. Retrieved from http://www.ibtimes.co.uk/aliaa-magdaelmahdy-nude-blogger-beaten-tahrir-256889

Milan, S. (2015). From social movements to cloud protesting: The evolution of collective identity. Information, Communication \& Society, 18(8), 887-900. doi:10.1080/1369118X.2015.1043135

Mottahedeh, N. (2015). \#iranelection: Hashtag solidarity and the transformation of online life. Ebook Central. Retrieved from https://ebookcentral.proquest.com

Namazi, M. (2011, December 14). Reminder: Call for submissions for nude photo revolutionaries calendar. Maryamnamazie.com. Retrieved from http:// maryamnamazie.com/reminder-call-for-submissions -for-nude-photo-revolutionaries-calendar

Nead, L. (1992). The female nude: Art, obscenity, and sexuality. London and New York, NY: Routledge.

Noorhan, B. [TheNoorBarakat]. (2011, November 12). When will people understand that stripping down for a 'cause' is absolute bull shit?! \#NudePhotoRevolutionary. Twitter. Retrieved from https://twitter.com/ TheNoorBarakat/statuses/135364910359126016

Poundstone, W. (2011, August 1). Dear Artforum: About that Lynda Benglis ad.... blogs.artinfo.com. Retrieved from http://blogs.artinfo.com/lacmonfire/ 2011/08/01/dear-artforum-about-that-lynda-benglis -ad...

Ratcliff, C. (n.d.). The fate of a gesture: Lynda Benglis. artnet.com. Retrieved from http://www.artnet.com/ magazine_pre2000/index/ratcliff/ratcliff6-13-97.asp

Stack, L., \& Kirkpatricknov, D. (2011, November 17). Nude blogger riles Egyptians of all stripes. New York Times. Retrieved from http://www.nytimes.com/ 2011/11/18/world/middleeast/aliaa-magda-elmahdy -egypts-nude-blogger-stirs-partisan-waters.html

Taghyer. (2011, November 24). Beating Aliaa Elmahdi in Tahrir. YouTube. Retrieved from https://www. youtube.com/watch?v=WJZcNjL7-K4

Taylor, V., \& Whittier, N. E. (1992). Collective identity in social movement communities: Lesbian feminist mobilization. In A. D. Morris \& C. M. Mueller (Eds.), Frontiers in social movement theory (pp. 104-129). New Haven, CT: Yale University Press.

Tifentale, A., \& Manovich, L. (2015). Selfiecity: Exploring photography and self-fashioning in social media. In D. M. Berry \& M. Dieter (Eds.), Postdigital aesthetics: Art, computation and design (pp. 109-122). London: Palgrave Macmillan.

Van Zoonen, L., Vis, F., \& Mihelj, S. (2010). Performing citizenship on YouTube: Activism, satire and online debate around the anti-Islam video Fitna. Critical Discourse Studies, 7(4), 249-262. doi:10.1080/ 17405904.2010.511831

Wilke, H. (1992). Intra-Venus series no. 3. Three chro- 
mogenic supergloss print. Feldman Gallery. Retrieved from http://feldmangallery.com/media/have \%20we\%20met\%20before/triptychdetail-01.jpg

Würger, T. (2013, December). From icon to exile: The price of a nude photo in Egypt. $A B C$ News. Retrieved from http://abcnews.go.com/International/iconexile-price-nude-photo-egypt/story?id=21287268

\section{About the Author}

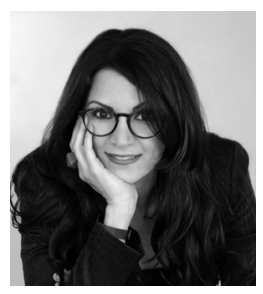

Mona Kasra is an Assistant Professor of Digital Media Design at the University of Virginia (UVa). A transdisciplinary scholar and a creative practitioner, she applies an interdisciplinary framework combining semiotics, visual studies, media theory, and cultural studies to examine the power and impact of online images upon cross-cultural and cross-political life in the networked age. In her work, she also employs, explores, and experiments with existing and emerging media in the context of art making, storytelling and installation. Mona has exhibited work in numerous gallery and online exhibitions and has programmed, curated, and served as a juror for several film festivals and art exhibitions. In 2016, she served as Conference Chair at ACM SIGGRAPH, undertaking an engaged role in the strategic planning, leading, and managing of the world's largest, most influential annual conference on the theory and practice of computer graphics and interactive techniques. 